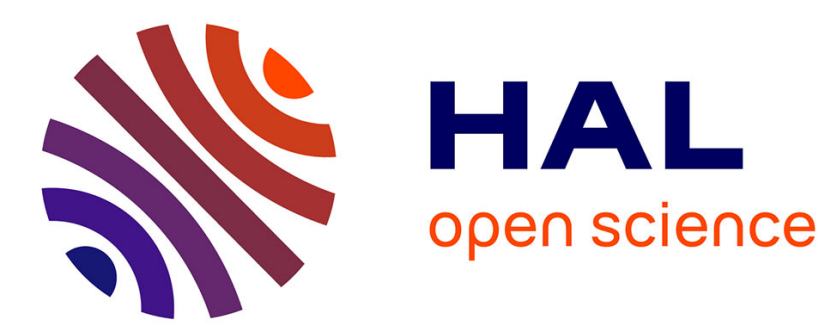

\title{
MANIFESTATION OF ATOMIC DYNAMICS THROUGH THE AUGER EFFECT
}

\author{
M. Krause, Tom Carlson, W. Moddeman
}

\section{To cite this version:}

M. Krause, Tom Carlson, W. Moddeman. MANIFESTATION OF ATOMlC DYNAMICS THROUGH THE AUGER EFFECT. Journal de Physique Colloques, 1971, 32 (C4), pp.C4-139-C4-144. 10.1051/jphyscol:1971425 . jpa-00214626

\section{HAL Id: jpa-00214626 https://hal.science/jpa-00214626}

Submitted on 1 Jan 1971

HAL is a multi-disciplinary open access archive for the deposit and dissemination of scientific research documents, whether they are published or not. The documents may come from teaching and research institutions in France or abroad, or from public or private research centers.
L'archive ouverte pluridisciplinaire HAL, est destinée au dépôt et à la diffusion de documents scientifiques de niveau recherche, publiés ou non, émanant des établissements d'enseignement et de recherche français ou étrangers, des laboratoires publics ou privés. 


\title{
MANIFESTATION OF ATOMIC DYNAMICS THROUGH THE AUGER EFFECT (*)
}

\author{
M. O. KRAUSE, T. A. CARLSON, and W. E. MODDEMAN ( $\left.{ }^{\dagger}\right)$ \\ Oak Ridge National Laboratory Oak Ridge, Tennessee U. S. A.
}

\begin{abstract}
Résumé. - Utilisant comme exemple le spectre Auger du néon, il est montré que le spectre Auger renferme des informations précises sur l'interaction du rayonnement, ou des particules, avec les électrons du cortège électronique et sur les mécanismes d'interaction électron-électron dans l'atome ionisé dans ses couches internes. On peut différencier les processus d'ionisation simple, d'ionisation double, d'ionisation-excitation, etc. Environ 90 lignes du spectre du néon sont classifiées d'après ces processus fondamentaux. Les énergies et les intensités relatives des lignes appartenant aux différents processus sont présentées et comparées avec la théorie et des résultats d'autres expériences. La dépendance du spectre au mode d'excitation est discutée.
\end{abstract}

\begin{abstract}
Using the neon Auger spectrum as an example, Auger spectra are shown to yield detailed information on the interaction of radiation or particles with atomic electrons and on the mechanics of electron-electron interaction of the innershell ionized atom. Processes such as simple ionization, simple excitation, double ionization, excitation-ionization, etc., can be distinguished and studied by way of Auger electron spectrometry. In accordance with the underlying physical processes we present a classification of the some 90 lines of the neon spectrum, obtained both by photon and electron excitation. Relative energies and intensities of the lines within the various categories are given, and compared with theory and data from different sources. Dependence of spectral intensities on excitation conditions is discussed.
\end{abstract}

I. Introduction. - Using the neon $K$-Auger spectrum as a demonstration object, we show that the various groups of normal and satellite Auger lines can be correlated with the various processes by which the atom is excited in the initial interaction and de-excited in the subsequent electron rearrangement. Thus, the Auger spectrum becomes a sensitive and useful probe of the dynamics that govern orbital electrons and their interactions with each other and with incident photons and particles.

In the past the "normal» Auger spectrum, and thus the interaction of orbital electron pairs, had been studied almost exclusively [1-3]. Only recently has the "satellite" Auger spectrum been studied. Certain satellite groups have been classified $[1,3]$ according to the underlying excitation mechanism and have been used to determine parameters of interactions of photons and particles with atoms [4-7].

In this paper we present the "complete» Auger spectrum of neon obtained with high energy resolution and classify the observed lines in groups according to the originating processes. We emphasize the qualitative conclusions of this analysis, although we draw a number of quantitative conclusions regarding intensities, energies and line designations. We also present data showing how different excitation condi-

(*) Research sponsored by the U. S. Atomic Energy Commission under contract with the Union Carbide Corporation.

(t) Guest student from the University of Tennessee, Knoxville, Tennessee, USA. tions may alter certain features of the spectrum, and how they may be used in doubtful cases to differentiate the various processes and resolve ambiguites that can be caused by interfering lines.

II. Classification of Auger Electron Lines. - The following categories of Auger lines are identified and related to definite excitation and rearrangement processes :

A. Normal or diagram lines arising from $K$-electron ionization : $1 \mathrm{~s} \rightarrow \infty$.

B. Satellite lines arising from $K$-electron excitation : $1 \mathrm{~s} \rightarrow n \mathrm{~s}, n \mathrm{p}, n \mathrm{~d} ; n \geqslant 3$. Two different decay modes are available for this configuration :

$\mathrm{B} \alpha)$ The excited electron, $n \geqslant 3$, is not involved in the Auger transition, but remains a spectator.

$\mathrm{B} \beta$ ) The excited electron participates in the Auger transition and is emitted.

C. Satellite lines arising from monopole excitation or shake-up : $1 \mathrm{~s}, 2 \mathrm{p} \rightarrow \infty, n \mathrm{p}$; or $1 \mathrm{~s}, 2 \mathrm{~s} \rightarrow \infty, n \mathrm{~s}$; with $n \geqslant 3$. Again, two different decay modes are possible :

$\mathrm{C} \alpha$ ) The excited electron, as spectator electron, is not involved in the Auger transition.

$C \beta$ ) The excited electron participates in the transition.

D. Satellite lines arising from monopole ionization or shake-off : $1 s, 2 p \rightarrow \infty, \infty$; or $1 s, 2 s^{\prime} \rightarrow \infty, \infty$. 
E. Satellite lines arising from excitation processes involving more than two electrons, especially from double shake-off.

F. Satellite lines arising from those double Auger processes [8] which lead to the emission of one $L$ electron and excitation of another.

$X$. Satellite lines amenable to categorization but not to precise or definitive identification.

$\mathrm{A}$ and $\mathrm{B}$ lines indicate initial single hole states of the atom, C and D lines double hole states, and $\mathrm{E}$ lines multiple hole states. F lines may arise from initial single or multiple hole states, but for reasons of intensity only the single hole state needs to be considered. The $\mathrm{X}$ lines cannot be assigned with absolute certainty; however, most of them can be placed into the categories $\mathrm{B} \alpha, \mathrm{C} \alpha, \mathrm{E}$ and $\mathrm{F}$ with a great degree of confidence.

For the sake of illustration, the above scheme is referred to the neon atom, but can readily be adapted to other atoms and to molecules [9].

III. Experimental. - Two double-focussing electrostatic energy analyzers with 15 and $20 \mathrm{~cm}$ radii, respectively, were used together with automatic data collection systems $[5,6]$ to record the neon Auger spectrum under both electron and X-ray bombardment. Data from the two spectrometers, each operated at an energy resolution of about $0.06 \%$ (FWHM), agreed excellently in all regards. The energy range from 700 to $880 \mathrm{eV}$ was scanned. Energy of incident electrons was usually between 4 and $5 \mathrm{keV}$ and that of the X-rays $1.5 \mathrm{keV}\left(\mathrm{Al} K_{\alpha}\right)$; however, other primary energies between 0.9 to $10 \mathrm{keV}$ were used for specific purposes. Pressures in the source were in the range from $10^{-3}$ to nearly $10^{-1}$ torr (absolute) and in the analyzer section in the $10^{-6}$ and lower $10^{-5}$ torr range. At these gas densities only small corrections needed to be applied to the spectra for characteristic energy losses. Since, despite the high-resolution, many peaks had to be resolved graphically, intensities quoted are peak values except those listed in Table I. Where

\section{TABLE I}

Relative Energies and Intensities of Normal $K$-Auger Lines of Neon (A-lines) due to 1s Electron Ionization. Initial state : $1 \mathrm{~s} 2 \mathrm{~s}^{2} 2 \mathrm{p}^{6}$.

\begin{tabular}{|c|c|c|c|c|}
\hline Line & $E \underset{(\mathrm{eV})}{E_{0}(a)}$ & $l / I_{0}(a)$ & Final $\mathbf{S}$ & tate $(b)$ \\
\hline$\overline{1}$ & & & & \\
\hline $\begin{array}{ll}\text { A } 1 \\
\text { A } 2\end{array}$ & $\begin{array}{l}-56.2(1) \\
-327(1)\end{array}$ & $\begin{array}{c}9.95(10) \\
28 .\end{array}$ & $2 \mathrm{~s} 2 \mathrm{p}^{0}$ & $1 \mathrm{P}_{1}$ \\
\hline A 3 & -22.2 (1) & 10.2 (3) & $2 \mathrm{~s} 2 \mathrm{p}^{5}$ & $3 \mathrm{P}_{012}$ \\
\hline A 4 & $-3.7(1)$ & 15.6 & $2 p^{4}$ & ${ }^{1} \mathbf{S}_{0}$ \\
\hline A 5 & 0 & 100.0 & $2 \mathrm{p}^{4}$ & ${ }^{1} \mathrm{D}_{2}$ \\
\hline A 6 & $+3.1(1)$ & $0.07(5)(c)$ & $2 p^{4}$ & ${ }^{3} \mathrm{P}_{02}$ \\
\hline
\end{tabular}

(a) Referred to line A $5 ; E_{0}=804.3$ (1) eV; $I_{0}=100.0$.

(b) In this and the following tables spectroscopic notations are used with a few exceptions.

(c) Line $\mathrm{B} \propto 2$ subtracted. comparison between peak and area values was possible, as for A lines, the two sets agreed well. Dispersion correction was applied to intensity data.

IV. Results and Discussion. - Figure 1 presents an overall view of almost the entire spectrum. Labels

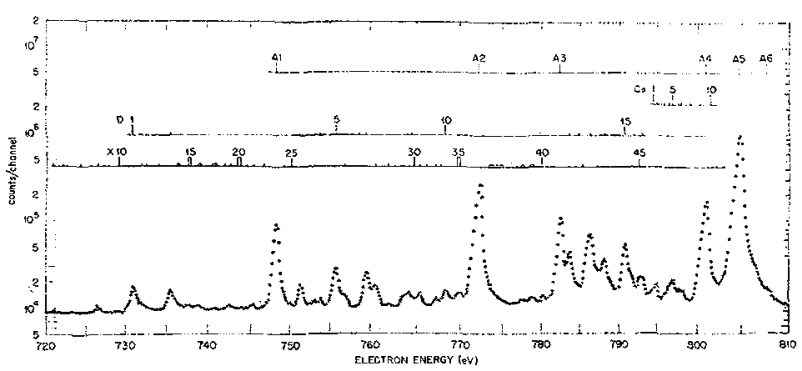

FIG. 1. - Neon K-Auger spectrum excited by $4.5 \mathrm{keV}$ electrons. Composite of three overlapping runs. Faint structure between 700 and $720 \mathrm{eV}$ omitted. Energy. resolution $0.06 \%$ FWHM. A-lines are diagram Auger lines ; $\mathrm{C} \alpha$-lines shakeup and $\mathrm{D}$ lines shake-off lines. $\mathrm{X}$-lines are lines of tentative assignment. Open rectangles, i. e., $X 20$, indicate broad peak.

refer to the classification outlined in Section II. It can be seen that the greater portion of the spectral intensity resides in processes of the type $A, D$ and $C \alpha$. A Lorentzian spread can be noted at the foot of each major line indicating the same order of magnitude for natural line width and instrumental line width. In such cases, it is possible to deduce absolute transition rates from the widths of the lines [2]. Table I lists relative energies and intensities of the normal or diagram Auger lines. Earlier intensity measurements $[2,3,5]$ agree well with present data, but theory is at variance even if it includes configuration interaction $[10,11]$. Since, according to Callan's [12] calculations, rates of the various Auger transitions are extremely sensitive to the type of wave functions used we can utilize Auger spectra to provide a most sensitive test of the quality of atomic wave functions. To exclude the possibility of satellite lines interfering with normal lines we carried out a special experiment in which satellite intensities are drastically reduced (see below), and concluded that none of the allowed A lines contains extraneous contributions exceeding $2 \%$ of their values. The forbidden line A 6 is an exception as seen in figure 2. When excited by electrons the line is masked by the $\mathrm{B} \propto 2$ satellite, but when excited by photons is free from interference, since B satellites appear with negligible intensity in spectra induced by photons from sources having strong characteristic lines above the bremsstrahlungs continuum. Accidental coincidences of X-ray lines with resonances, such as Ti $L \eta$ with $\mathrm{N}_{2}$ (1s $\rightarrow \pi \mathrm{g} 2 \mathrm{p}$ ), can usually be predicted. The present value of $I / I_{0}=0.07(5) \%$ for the intensity ratio of $A 6$ and $A 5$ lines constitutes a much weaker violation of the $L S$ coupling scheme than was suggested earlier $[3,5]$.

The B satellites offer a unique opportunity for studying discrete transitions $1 \mathrm{~s} \rightarrow n s, n \mathrm{p} .$. with incident 


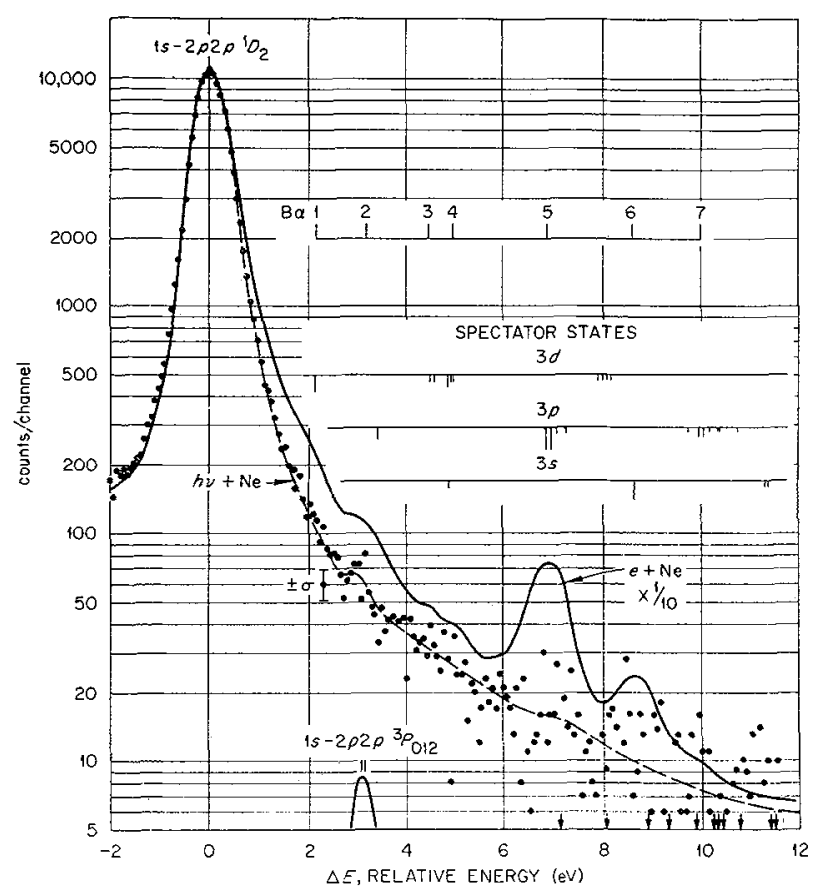

FIG. 2. - High-energy tail of $1 s-2 p 2 p 1 D$ Auger line (A 5) excited by $1,5 \mathrm{keV}$ Al $K_{\alpha}$ X-rays (dots) and by $3.5 \mathrm{keV}$ electrons (solid line). $\mathrm{B} \alpha$-lines, reflecting $1 \mathrm{~s}-n \mathrm{~s}, n \mathrm{p}, n \mathrm{~d}$ transitions, appear only under electron bombardment. Tick marcks for spectator states are calculated positions. Average background of about $0.3 \%$ of main peak subtracted from both runs. $\Delta E / E=0,06 \%$. Note, A 6 line $\left(2 \mathrm{p} 2 \mathrm{p}{ }^{3} \mathrm{P}\right)$ is masked by $\mathrm{B} \alpha 2$ in electron induced spectrum.

electrons. Inspecting figure 2 we find dipole transitions $1 \mathrm{~s} \rightarrow n \mathrm{p}$ to be dominant at a primary electron energy of $3.5 \mathrm{keV}$. Considering intensities of all B satellites summarized in Table II, together with energies and final state identification, we note that $1 \mathrm{~s}$ electron excitation takes place in about $2 \%$ of the collisions and ionization in $98 \%$ of the events. This value

\section{TABLE II}

Relative Energies and Intensities of B-Satellites, due to $1 \mathrm{~s}$ Electron Excitation. Parent Lines are A 4 and A 5. Initial state : $1 \mathrm{~s} 2 \mathrm{~s}^{2} 2 \mathrm{p}^{6} n \mathrm{~s} ; n \mathrm{p}$; $n \mathrm{~d}$.

\begin{tabular}{ccll} 
Line & $E-E_{0}(a)$ & \multicolumn{1}{c}{$I / I_{0}(a)$} & Final State( ${ }^{(a)}$ \\
- & $(\mathrm{eV})$ & - & \multicolumn{1}{c}{-} \\
$\overline{\mathrm{B} \alpha 1}$ & $2.1(2)$ & $0.04(2)$ & $2 \mathrm{p}^{4}(1 \mathrm{~S}) 3 \mathrm{~d}(2 \mathrm{D})$ \\
$\mathrm{B} \alpha 2$ & $3.2(2)$ & $0.14(5)\left({ }^{c}\right)$ & $2 \mathrm{p}^{4}(1 \mathrm{~S}) 3 \mathrm{p}(2 \mathrm{P})$ \\
$\mathrm{B} \alpha 3$ & $4.2(3)$ & $0.08(3)$ & $2 \mathrm{p}^{4}(1 \mathrm{D}) 3 \mathrm{~d}(2 \mathrm{~S})$ \\
$\mathrm{B} \alpha 4$ & $5.0(3)$ & $0.16(4)$ & $3 \mathrm{p}^{4}(1 \mathrm{D}) 3 \mathrm{~d}(2 \mathrm{D})$ \\
$\mathrm{B} \alpha 5$ & $6.8(3)$ & $0.92(8)$ & $2 \mathrm{p}^{4}(1 \mathrm{D}) 3 \mathrm{p}(2 \mathrm{D})$ \\
$\mathrm{B} \alpha 6$ & $8.6(3)$ & $0.28(4)$ & $2 \mathrm{p}^{4}(1 \mathrm{D}) 3 \mathrm{~s}(2 \mathrm{D})$ \\
$\mathrm{B} \alpha 7$ & $10.0(4)$ & $0.09(5)$ & $2 \mathrm{p}^{4}(3 \mathrm{P}) 3 \mathrm{p}(2 \mathrm{D})$ \\
$\Sigma \mathrm{B} \alpha(a)$ & 2 to 10 & $1.7(2)$ & $2 \mathrm{p}^{4} 3 \mathrm{~s} ; 3 \mathrm{p} ; 3 \mathrm{~d}$ \\
$\Sigma \mathrm{B} \beta(e)$ & 39 to 43 & $0.05(2)$ & $2 \mathrm{p}^{5}(2 \mathrm{P})$ \\
$\Sigma \mathrm{B}-\mathrm{sat}$. & - & $1.8(2)$ &
\end{tabular}

(a) Referred to line A $5 ; E_{0}=804.3 \mathrm{eV} ; I_{0}=100.0$.

(b) Only major contribution indicated.

(c) Line A 6 subtracted.

(d) Excited electron remains spectator.

(e) Excited electron participates in transition as actor. remains approximately the same over the energy range from 2 to $6 \mathrm{keV}$ for which we have data. Similarly, dipole transitions remain dominant through the range.

The $\mathrm{B} \alpha$ lines are associated with a decay mode in which the excited electron remains in its orbit as spectator, while $\mathrm{B} \beta$ lines are associated with the less frequent decay mode of the exciting electron participating in the transition. The intensity ratio of $\Sigma \mathrm{B} \beta / \Sigma \mathrm{B} \alpha$, normalized per electron, is about 0.15 , a reasonable value compared to analogous $K L X / K L L$ intensity ratios [15]. Indicated peak positions of $B \alpha$ lines in figure 2 , and $\mathrm{B} \beta$ lines in figure 3 were calculated using Wuilleumier's data [13] for $1 \mathrm{~s} 2 \mathrm{~s}^{2} 2 \mathrm{p}^{6} n \mathrm{p}$ states and Moore's values [14] for final states. Energies of $n \mathrm{~s}$ and $n d$ states were evaluated from $\mathrm{Na}$ levels.

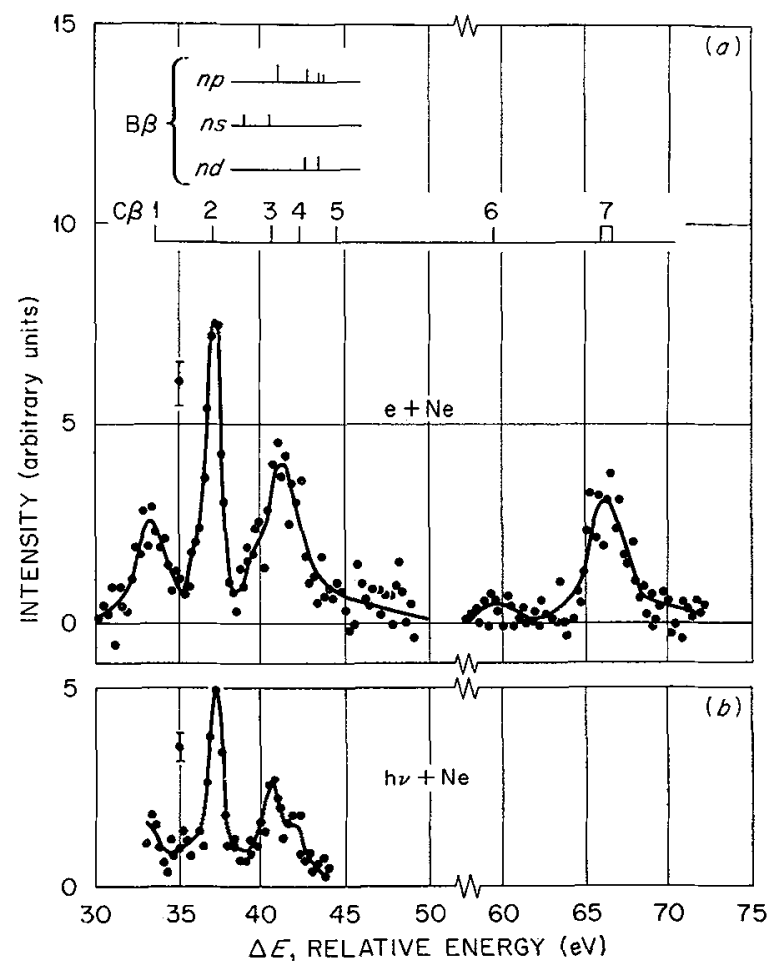

FIG. 3. $-K-L X$ spectrum of neon, following population of $n=3,4 \ldots$ levels by shakeup excitation ( $\mathrm{C} \beta$ lines) or $1 \mathrm{~s}$ excitation (B $\beta$ lines). Spectra produced by $4.5 \mathrm{keV}$ electrons (a), and by Al $K_{\alpha}$ X-rays (b). Background substracted ; $\Delta E / E=0.1 \%$; energies relative to that of $\mathrm{A} 5$ line. Positions of $\mathrm{B} \beta$ and $\mathbf{C} \beta 1$ to $\mathrm{C} \beta .5$ lines are calculated.

Satellites of category $\mathrm{C}$ characterize two-electron transitions with one electron going to a discrete level and the other to the continuum. $\mathrm{C} \alpha$-lines are grouped together on the immediate low-energy side of the respective A parent lines. For example, the more intense $\mathrm{C} \alpha$ lines associated with $\mathrm{A} 4$ and $\mathrm{A} 5$ are designated in figure 1. The $\mathrm{C} \beta$ lines appear about $40 \mathrm{eV}$ above the parent line (figure 3 ). As for B-lines, the intensity ratio of $\Sigma \mathrm{C} \beta / \Sigma \mathrm{C} \alpha$ is small, namely 0.13 when normalized per electron. The shakeup probability of about $6 \%$ for a $2 \mathrm{p}$ electron going into the $3 \mathrm{p}$ level, as deduced from the intensity ratio of $\Sigma \mathrm{C} /(\mathrm{A} 4+\mathrm{A} 5)$ is in good agreement with results from photoelectron 
spectra $[3,16]$. The Auger satellite spectrum of figure $3 b$ and the photoelectron spectrum near $-40 \mathrm{eV}$ of figure 1 of Ref. [16] represent mirror images as far as the energies are concerned, because the same energy that the photoelectron loses in the monopole excitation is gained by the corresponding Auger electron in the subsequent de-excitation. Identification of C-lines is made in Table III.

The D satellites are characteristic of shakeoff processes. Although these lines have been identified before [1] as well as used for testing certain aspects of the shakeoff theory $[5,7]$ we present here in Table IV relative energies and intensities with improved accuracy. Shakeoff probability for $K L$ ionization defined as the intensity of all $\mathrm{D}$ lines over that of all $\mathrm{A}$ and $\mathrm{D}$ lines amounts to $13.8 \%$. This value together with the value for shakeup events is compatible with results from experiments of different types [16, 17].

Table $\mathrm{V}$ includes all lines observed and resolved which resist definitive identification. On the basis of position and intensity we are able to place most of the lines into the various categories of Section II. Remaining lines are probably due to processes involving more than two electrons.

Figure 4 shows that the satellite structure can be depressed by the proper choice of excitation conditions. Because of the small excess energy of $\mathrm{Cu} L_{\alpha}$ $\mathrm{X}$-rays over the $K L$ ionization energy the shake-off

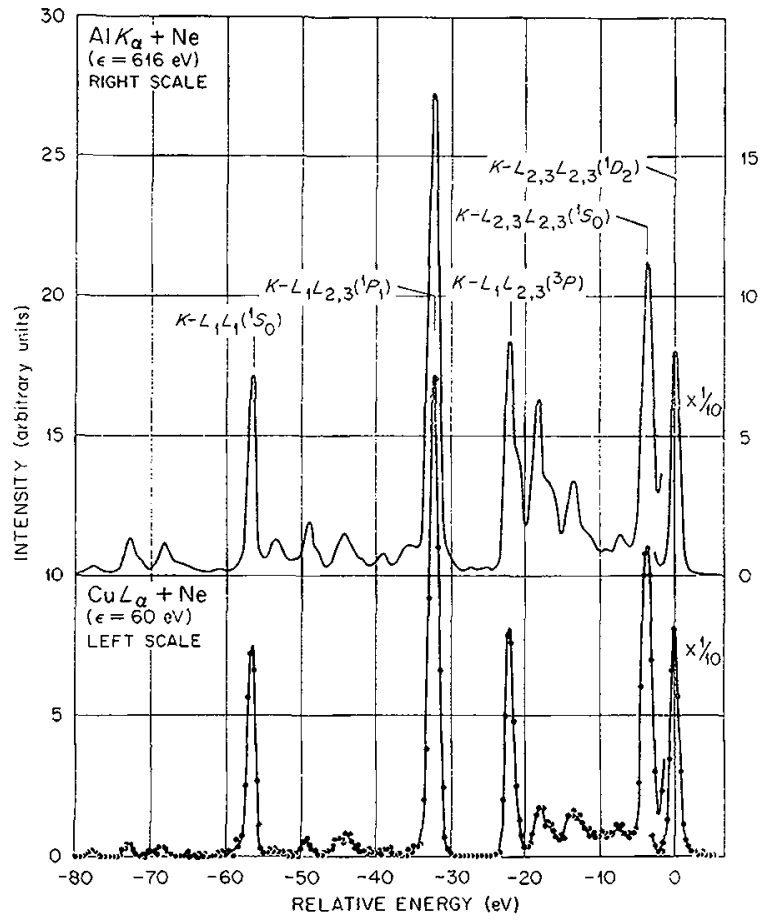

FIG. 4. - Neon $K$-Auger spectrum, illustrating reduction of satellite intensities by using photons near $K L$ ionization threshold for excitation. Large portion of remaining structure is due to higher-energy bremsstrahlung. Upper spectrum is taken from Ref. $5 . \Delta E / E=0.17 \%$. Note invariance of diagram line against excitation conditions.

TABLE III. - Relative Energies and Intensities of C-Satellites due to Monopole Excitation. Parent Lines are A 4 and A 5. Initial state: $1 \mathrm{~s} 2 \mathrm{~s}^{2} 2 \mathrm{p}^{5} n \mathrm{p}$

\begin{tabular}{|c|c|c|c|c|c|}
\hline \multirow[b]{2}{*}{ Line } & \multicolumn{2}{|c|}{$E-E_{0}(\mathrm{eV})\left({ }^{a}\right)$} & \multirow[b]{2}{*}{$I / I_{0}\left({ }^{a}\right)$} & \multirow[b]{2}{*}{ Initial State $\left(^{b}\right)$} & \multirow[b]{2}{*}{ Final State } \\
\hline & Exp. & Calc. $\left({ }^{c}\right)$ & & & \\
\hline $\mathrm{C} \alpha 1$ & $-10.4(3)$ & -10.6 & $0.5(2)$ & $3 \mathrm{p} \mathrm{low}$ & $2 \mathrm{p}^{3}\left({ }^{2} \mathrm{P}\right) 3 \mathrm{p}\left({ }^{3} \mathrm{P}\right)$ \\
\hline $\mathrm{C} \propto 2$ & $-10.0(2)$ & -10.3 & $0.8(2)$ & 3 p low & $2 \mathrm{p}^{3}\left({ }^{2} \mathrm{P}\right) 3 \mathrm{p}\left({ }^{3} \mathrm{D}\right)$ \\
\hline$C \propto 3$ & $-9.0(2)$ & -8.9 & $0.2(1)$ & 3 p low & $2 \mathrm{p}^{3}\left({ }^{2} \mathrm{D}\right) 3 \mathrm{p}\left({ }^{3} \mathrm{P}\right)$ \\
\hline $\mathrm{C} \alpha 4$ & $-8.3(3)$ & -8.0 & $0.4(2)$ & 3 p low & $2 \mathrm{p}^{3}\left({ }^{2} \mathrm{D}\right) 3 \mathrm{p}\left({ }^{3} \mathrm{~F}\right)$ \\
\hline $\mathrm{C} \propto 5$ & $-7.9(2)$ & -7.7 & $1.1(2)$ & 3 p low & $2 \mathrm{p}^{3}\left({ }^{2} \mathrm{D}\right) 3 \mathrm{p}\left({ }^{3} \mathrm{D}\right)$ \\
\hline $\mathrm{C} \alpha 6$ & $-7.0(2)$ & -7.2 & $0.6(2)$ & 3 p up & $2 p^{3}\left({ }^{2} P\right) 3 p\left({ }^{3} P\right)$ \\
\hline $\mathrm{C} \propto 7$ & $-6.6(2)$ & -6.9 & $0.5(2)$ & $3 \mathrm{p} \mathrm{up}$ & $2 \mathrm{p}^{3}\left({ }^{2} \mathrm{P}\right) 3 \mathrm{p}\left({ }^{3} \mathrm{D}\right)$ \\
\hline $\mathrm{C} \alpha 8$ & $-5.6(3)$ & -5.5 & $0.2(1)$ & $3 \mathrm{p}$ up & $2 \mathrm{p}^{3}\left({ }^{2} \mathrm{D}\right) 3 \mathrm{p}\left({ }^{3} \mathrm{P}\right)$ \\
\hline $\mathrm{C} \times 9$ & $-4.3(2)$ & -4.2 & $2.0(4)$ & $3 \mathrm{p}$ up & $2 p^{3}\left({ }^{2} D\right) 3 p\left({ }^{3} D\right)$ \\
\hline $\mathrm{C} \alpha 10$ & - & -3.2 & - & 3 p low & $2 \mathrm{p}^{3}\left({ }^{4} \mathrm{~S}\right) 3 \mathrm{p}\left({ }^{5} \mathrm{P}\right)$ \\
\hline $\mathrm{C} \alpha 11$ & - & +0.2 & - & $3 \mathrm{p} \mathrm{up}$ & $2 \mathrm{p}^{3}\left({ }^{4} \mathrm{~S}\right) 3 \mathrm{p}\left({ }^{5} \mathrm{P}\right)$ \\
\hline$C \beta 1$ & $33.0(5)$ & 33.6 & $0.02(1)$ & 3 p low & $2 \mathrm{p}^{4}\left({ }^{1} \mathrm{~S}\right)$ \\
\hline$C \beta 2$ & $37.4(3)$ & 37.3 & $0.06(1)$ & 3 p low & $2 p^{4}\left({ }^{1} D\right)$ \\
\hline$C \beta 3$ & 40.9 (3) & 40.7 & $0.03(1)$ & $3 \mathrm{p} \mathrm{up}$ & $2 p^{4}\left({ }^{1} D\right)$ \\
\hline$C \beta 4$ & $41.9(3)$ & 42.4 & 0.01 & $4 \mathrm{p}$ low & $2 \mathrm{p}^{4}\left({ }^{1} \mathrm{D}\right)$ \\
\hline$C \beta 5$ & - & 44.4 & 0.005 & 5 p low & $2 p^{4}\left({ }^{1} D\right)$ \\
\hline$C \beta 6$ & $59(1)$ & - & 0.01 & $n \mathrm{p}^{2} ; 3 \mathrm{~s}(?)$ & - \\
\hline$C \beta 7$ & $66(1)$ & 一 & $0.03(1)$ & $n \mathrm{p}^{2} ; 4 \mathrm{~s}(?)$ & 一 \\
\hline$\Sigma C \alpha\left({ }^{d}\right)$ & 0 to -11 & - & $6.3(7)$ & $3 p$ & $2 p^{3} 3 p$ \\
\hline$\Sigma C \beta\left({ }^{e}\right)$ & 33 to 66 & - & $0.16(3)$ & $n \mathrm{p} ; n \mathrm{~s}$ & $2 \mathrm{p}^{4}$; others \\
\hline
\end{tabular}

$\left({ }^{a}\right)$ Referred to line A $5 ; E_{0}=804.3 \mathrm{eV} ; I_{0}=100.0$.

$\left({ }^{b}\right)$ Excited electron state (see Ref. 3 and 16 ); higher states, $n \geqslant 4$, may contribute in some places. (Ref. 14).

${ }^{c}$ ) Calculated by using experimental energies for initial state (Ref. 16), and Moore's tables for final state

( $\left.{ }^{d}\right)$ Excited electron remains in spectator state.

( ${ }^{e}$ Excited electron participates; only major energy range denoted. 
TABLE IV

Relative Energies and Intensities of D Satellites due to Monopole Ionization. Parent Lines A 1 to A 6. Initial state $1 \mathrm{~s} 2 s^{2} 2 p^{5}$, and $1 \mathrm{~s} 2 \mathrm{~s} 2 \mathrm{p}^{6}$.

\begin{tabular}{|c|c|c|c|c|c|}
\hline \multirow{2}{*}{ Line } & \multicolumn{2}{|c|}{$E-E_{0}(\mathrm{eV})\left({ }^{a}\right)$} & \multirow[b]{2}{*}{$I / I_{0}\left({ }^{a}\right)$} & \multirow[b]{2}{*}{ Initial State $\left({ }^{b}\right)$} & \multirow[b]{2}{*}{ Final State } \\
\hline & Exp. & Calc. $\left(^{(}\right)$ & & & \\
\hline D 1 & $-73.9(2)$ & -73.4 & $1.2(1)$ & $2 \mathrm{p}^{5}\left({ }^{3} \mathrm{P}\right)$ & $2 \mathrm{~s}^{0} \overline{2 \mathrm{p}^{5}\left({ }^{2} \mathrm{P}\right)}$ \\
\hline D 2 & $-69.2(2)$ & -68.7 & 0.9 (2) & $2 \mathrm{p}^{5}\left({ }^{1} \mathrm{P}\right)$ & $2 \mathrm{~s}^{0} 2 \mathrm{p}^{5}\left({ }^{2} \mathrm{P}\right)$ \\
\hline D 3 & $-53.3(1)$ & -53.0 & 1.1 (1) & $2 \mathrm{p}^{5}\left({ }^{3} \mathrm{p}\right)$ & 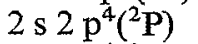 \\
\hline D 4 & $-50.7(2)$ & -50.4 & 0.2 (1) & $2 \mathrm{p}^{5}\left({ }^{3} \mathrm{P}\right)$ & $2 \mathrm{~s} 2 \mathrm{p}^{4}\left({ }^{2} \mathrm{~S}\right)$ \\
\hline D 5 & $-48.7(1)$ & -48.3 & 2.3 (1) & $2 \mathrm{p}^{5}\left({ }^{1} \mathrm{P}\right)$ & $2 \mathrm{~s} 2 \mathrm{p}^{4}\left({ }^{2} \mathrm{P}\right)$ \\
\hline D 6 & $-45.7(3)$ & -45.5 & $0.12(5)$ & $2 \mathrm{p}^{5}\left({ }^{1} \mathbf{P}\right)$ & $2 \mathrm{~s} 2 \mathrm{p}^{4}\left({ }^{2} \mathrm{~S}\right)$ \\
\hline D 7 & $-45.0(1)$ & -44.8 & 1.8 (1) & $2 \mathrm{p}^{5}\left({ }^{3} \mathrm{P}\right)$ & $2 \mathrm{~s} 2 \mathrm{p}^{4}\left({ }^{2} \mathrm{D}\right)$ \\
\hline D 8 & $-41.0(3)$ & -41.0 & $\approx 0.2$ & $2 \mathrm{~s}\left({ }^{1} \mathrm{~S}\right)$ & $2 s^{0} 2 p^{5}\left({ }^{2} P\right)$ \\
\hline D 9 & $-40.5(3)$ & -40.1 & $\approx 0.1$ & $2 \mathrm{p}^{5}\left({ }^{1} \mathrm{P}\right)$ & $2 \mathrm{~s} 2 \mathrm{p}^{4}\left({ }^{2} \mathrm{D}\right)$ \\
\hline D 10 & $-36.4(2)$ & -36.2 & $\approx 0.3$ & $2 \mathrm{p}^{5}\left({ }^{3} \mathrm{P}\right)$ & $2 \mathrm{~s} 2 \mathrm{p}^{4}\left({ }^{4} \mathrm{P}\right)$ \\
\hline D 11 & $-21.2(1)$ & -21.0 & $3.2 \quad(2)$ & $2 \mathrm{p}^{5}\left({ }^{3} \mathrm{P}\right)$ & $2 \mathrm{p}^{3}\left({ }^{\frac{2}{}} \mathrm{P}\right)$ \\
\hline D 12 & $-20.4(3)$ & -20.7 & 0.3 (1) & $2 \mathrm{~s}\left({ }^{3} \mathrm{~S}\right)$ & $2 \mathrm{~s} 2 \mathrm{p}^{4}\left({ }^{2} \mathrm{P}\right)$ \\
\hline D 13 & $-18.4(1)$ & -18.3 & $6.6(2)$ & $2 \mathrm{p}^{5}\left({ }^{3} \mathrm{P}\right)$ & $2 \mathrm{p}^{3}\left({ }^{2} \mathrm{D}\right)$ \\
\hline D 14 & $-16.7(2)$ & -16.4 & $2.4 \quad(3)\left({ }^{d}\right)$ & $2 \mathrm{p}^{5}\left({ }^{1} \mathrm{P}\right)$ & $2 \mathrm{p}^{3}\left({ }^{2} \mathrm{P}\right)$ \\
\hline D 15 & $-13.9(1)$ & -13.7 & 4.8 (1) & $2 \mathrm{p}^{5}\left({ }^{1} \mathrm{P}\right)$ & $2 \mathrm{p}^{3}\left({ }^{2} \mathrm{D}\right)$ \\
\hline D 16 & $-12.0(3)$ & -12.5 & $\approx 0.8$ & $2 \mathrm{~s}\left({ }^{3} \mathrm{~S}\right)$ & $2 \mathrm{~s} 2 \mathrm{p}^{4}\left({ }^{2} \mathrm{D}\right)$ \\
\hline D & & & $26.3(1.3)$ & $K L$ & $L^{3}$ \\
\hline
\end{tabular}

$\left({ }^{a}\right)$ Referred to line A $5 ; E_{0}=804.3 \mathrm{eV} ; I_{0}=100.0$.

$\left(b^{b}\right)$ With one 1 s electron removed.

$\left(^{c}\right)$ With $E_{\mathrm{K}}=870.1 \mathrm{eV} ; E_{2 \mathrm{p}, \mathrm{K}}=917.1 \mathrm{eV}$ and $921.8 \mathrm{eV} ; E_{2 \mathrm{~s}, \mathrm{~K}}=950 \mathrm{eV}$ for initial states, and Moore's optical data for final states.

(d) $0.4 \%$ of A 5 line subtracted for characteristic collision loss peak.

TABLE V

Relative Energies and Intensities of X-Satellites Arising from Various Multiple Excitation Processes. Probable Classification Indicated in First Column in Parentheses $\left({ }^{a}\right)$

\begin{tabular}{|c|c|c|c|c|c|}
\hline Line & $E-E_{0}(b)(\mathrm{eV})$ & $I / I_{0}(b)$ & Line & $E-E_{0}(\mathrm{eV})$ & $I / I_{0}$ \\
\hline$\times 1$ & $-98.0(3)$ & $0.04(2)$ & $\times 25$ & $-54.6(3)$ & $0.15(7)$ \\
\hline$\times 2$ & $-95.8(5)$ & $0.07(2)$ & X $26(B \alpha)$ & $-51.5(2)$ & $0.15(3)$ \\
\hline$\times 3$ & $-92 \quad(1)$ & $0.09(3)$ & $\times 27$ (E) & $-47.8(3)$ & $0.25(8)$ \\
\hline X 4 & $-87.7(3)$ & $0.07(1)$ & X $28(\mathrm{E})$ & $-44.0(2)$ & 0.9 (1) \\
\hline $\mathrm{X} 5(\mathrm{~F})$ & $-86.1(3)$ & $0.07(1)$ & $\times 29$ (F) & $-42.7(2)$ & $0.10(3)$ \\
\hline $\mathrm{X} 6$ & $-84.0(2)$ & $0.12(2)$ & X $30(\mathrm{C} \alpha)$ & $-40.0(3)$ & $0.12(5)$ \\
\hline$\times 7$ & $-82.7(3)$ & $0.04(1)$ & $X 31(\mathrm{C} \alpha)$ & $-39.3(2)$ & $0.52(6)$ \\
\hline X 8 & $-80.5(4)$ & $0.10(2)$ & $\mathrm{X} 32(\mathrm{C} \alpha)$ & $-38.7(2)$ & $0.05(3)$ \\
\hline$\times 9$ & $-78.2(2)$ & $0.26(3)$ & $\mathrm{X} 33(\mathrm{C} \alpha)$ & $-37.6(2)$ & $0.26(6)$ \\
\hline X $10(F)$ & $-75.7(2)$ & $0.08(1)$ & X $34(C \alpha)$ & $-36.9(3)$ & $0.07(3)$ \\
\hline $\mathrm{X} 11(\mathrm{~F})$ & $-72.7(3)$ & $0.22(5)$ & $X 35(\mathrm{C} \alpha)$ & $-35.1(3)$ & $0.5 \quad(1)$ \\
\hline $\mathrm{X} 12(\mathrm{~F})$ & $-72.0(3)$ & $0.10(5)$ & $\mathrm{X} 36(\mathrm{~B} \alpha)$ & $-30 \quad$ (1) & $0.8 \quad(2)$ \\
\hline$\times 13$ & $-70.9(3)$ & $0.07(2)$ & $X 37(\mathrm{C} \alpha)$ & $-28.2(3)$ & $0.05(2)$ \\
\hline$\times 14$ & $-68.5(3)$ & $0.24(8)$ & X $38(\mathrm{~B} \alpha)$ & $-27.2(3)$ & $0.18(5)$ \\
\hline $\mathrm{X} 15(\mathrm{C} \alpha)$ & $-67.3(2)$ & $0.22(4)$ & X $39(\mathrm{C} \alpha)$ & -25.9 (3) & $0.32(8)$ \\
\hline $\mathrm{X} 16(\mathrm{C} \alpha)$ & $-66.2(2)$ & $0.20(4)$ & $X 40(\mathrm{C} \alpha)$ & $-24.5(2)$ & $0.21(5)$ \\
\hline$X 17(C \alpha)$ & $-64.5(3)$ & $0.03(1)$ & $\mathrm{X} 41$ & $-19.0(3)$ & $0.2 \quad(1)$ \\
\hline X $18(\mathrm{C} \alpha)$ & $-63.4(3)$ & $0.02(1)$ & $\mathrm{X} 42$ & $-17.8(3)$ & 0.4 (2) \\
\hline$X 19(\mathrm{C} \alpha)$ & $-62.8(2)$ & $0.20(3)$ & $\times 43$ & $-15.6(2)$ & $0.5 \quad(1)$ \\
\hline$X 20(C \alpha)$ & $-61.3(4)$ & $0.08(3)$ & $\mathrm{X} 44$ & $-13.0(2)$ & $0.9(1)$ \\
\hline $\mathrm{X} 21(\mathrm{C} \alpha)$ & $-60.1(1)$ & $0.13(5)$ & $\mathrm{X} 45$ & $-12.1(2)$ & 0.8 (1) \\
\hline$X 22(C \alpha)$ & $-59.3(2)$ & $0.24(4)$ & $X 46(C \alpha)$ & $-2.6(2)$ & $0.8 \quad(2)$ \\
\hline$X 23(F)$ & $-57.3(3)$ & $0.15(5)$ & $\mathrm{X} 47(\mathrm{C} \alpha)$ & $-1.8(2)$ & 1.0 (2) \\
\hline X 24 & $-55.4(2)$ & $0.65(15)$ & & & \\
\hline
\end{tabular}

$\left({ }^{a}\right)$ For example, line $\mathrm{X} 15$ is probably a monopole excitation line $(\mathrm{C} \alpha)$, which is associated with $\mathrm{A} 1$.

(b) Referred to line A $5 ; E_{0}=804.3 \mathrm{eV} ; I_{0}=100.0$. 
probability is strongly reduced [18] while shakeup lines seem to remain intense even near threshold according to the present findings. Whether satellites interfere with diagram lines in spectra such as the commonly measured spectra of figure 1 or $4 a$ can be decided with the aid of the nearly pure diagram line spectrum of figure $4 b$. No interference is noted.

V. Conclusions. - A « complete » Auger spectrum, the neon Auger spectrum, has been recorded with a high-resolution electron spectrometer and has been interpreted in terms of the interactions that take place during excitation and de-excitation of the atom. This interpretation is not restricted to the neon atom but can be applied to other atoms and molecules. Thus, Auger spectra serve well in studies of collision processes, atomic wave functions and generally, the dynamics of orbital electrons.

\section{References}

[1] Körber (H.) and Mehlhorn (W.), Z. Physik, 1966, 191, 217 ; Stalherm (P.), Cleff (B.), Hillig (H.), and MEHLHORN (W.), Z. Naturforsch., 1969, 24a, 1728.

[2] Mehlhorn (W.), Stalherm (D.) and Verbeek (H.), Z. Naturforsch., 1968, 23a, 287.

[3] Siegbahn (K.), et al. : "ESCA Applied to Free Molecules ), North Holland Publishing Company, Amsterdam-London, 1969. PariLIS (E. S.), « The Auger Effect ), ed. by Arifov, (U. A.) Academy of Sciences, U. S. S. R., Tashkent, 1969.

[4] Edwards (A. K.) and Rudd (M. E.), Phys. Rev., 1968, 170, 140. GLUPE (G.) and MEHLHORN (W.), Physics Letters, 1967, 25A, 274. In these papers normal Auger lines are utilized primarily.

[5] Krause (M. O.), Stevie (F. A.), Lewis (L. J.), CarlSON (T. A.) and ModDeman (W. E.), Phys. Letters, $1970,31 \mathrm{~A}, 81$.

[6] Carlson (T. A.), Moddeman (W. E.), Pullen (B. P.) and Krause (M. O.), Chem. Phys. Letters, 1970, 5,390 .

[7] Carlson (T. A.), Krause (M. O.) and Moddeman (W. E.), Phys. Rev., 1970, A1, 1406.
[8] Carlson (T. A.) and Krause (M. O.), Phys. Rev. Letters, 1965, 14, 390 and 1966, 17, 1079.

[9] See for example, Moddeman (W. E.), Thesis, University of Tennessee, 1970 (unpublished); and Ref. 1, 3 and 6.

[10] See for example, Mehlhorn (W.) and Asaad (W. N.), Z. Physik, 1966, 191, 231.

[11] Asaad (W. N.), Nucl. Phys., 1965, 66, 494.

[12] Callan (E. J.) (private communication).

[13] WuIlleumier (F.), Thesis (unpublished) University of Paris, 1969.

[14] Moore (C. E.), Circular 467, 1949, National Bureau of Standards, Washington, D. C.

[15] Rubenstein (R. A.), Thesis, University of Illinois, 1955 (unpublished).

[16] Carlson (T. A.), Krause (M. O.) and Moddeman (W. E.), J. Physique, this issue, 76.

[17] Krause (M. O.), Carlson (T. A.) and DisMUKes(R. D.), Phys. Rev., 1968, 170, 37.

[18] Without bremsstrahlungs/contributions satellites would be even weaker. See also Ref. 7 . 